The Geneva Papers on Risk and Insurance, 16 (No. 61, October 1991), 419-423

\title{
Services, Globalization and Regulation
}

\author{
by J. Saint-Geours*
}

\section{Introduction}

It is a special pleasure to take part in this second Geneva forum. I say the second Geneva forum because the exact title of your meeting is just too complex: "global services and trade liberalization" brings no less than four major concepts together in ways which, I will try to show, are bound to be less than straightforward!

Let me pay tribute to the special talent of Orio Giarini in putting highly complex subjects on the table and in generating the ideas that later make them appear as simple. After all, he is also the Director of a think-tank with a very long name on the economics of insurance and services which everybody simply knows as "the Geneva Association"...

I met Orio at the Club of Rome when he was leading our collective discussions on the "diminishing returns of technological progress". It is a special pleasure to share with him tonight in a collective thinking on the "exploding returns" of such technological breakthroughs as global electronic networks.

I will talk briefly about two of the four words in your Symposium's title-namely services and globalization. Then, without ignoring your last two words - trade liberalization - I will use the privilege of the dinner speaker to introduce a word of my own on the need for a global regulatory framework.

\section{Services and globalization}

I am not surprised that a high caliber group like this one can now meet regularly to talk about services. Such meetings have to address the new problems raised by the globalization and internationalization of services which are the consequences of technical thrusts and new ways of managing the economic and financial world. New ways that are - as we shall see - a mix of a policy of rules (authorizations, restrictions) and of a regulatory policy (regulation of behaviors, prudential rules, systematic regulation). Services, even in the least developed societies, have always been a major part of the economy. In the financial sector, internationalization is a century old affair. In the 15 th and 16th century, it became possible to travel throughout Europe - from Genoa to Barcelona or the Hanseatic league - with

\footnotetext{
* President, COB (Commission des Opérations de Bourse) Paris. Comments delivered at the Second Geneva Forum on Services Liberalization, May 21, 1991
} 
lettres de change that a simple signature made possible to convert into local currency. But now the volume, the diversity, the sophistication, the rapidity of services, particularly the financial services continue to change our relationship to time and space.

Services are not just "globalizing" - to use the buzzword of the day -, they are changing what globalization is about.

First, the new relationship to space: services - exccpt, prcciscly, some financial scrvices - used to be seen as the less advanced, Icss mobile and most "national" part of the economy becausc they needed buyers and sellers to be together whereas goods could travel all over the world.

Today by contrast, information technology makes it possible for services to travel faster to any place in the world than almost any good. Also, the type of proximity that they creatc is no longcr understandable in geographic terms: new electronic spaces can be created. At the same time, subtle differences in culture that geographers did not notice can become major distances.

Thus, the localization of activities is based today on new criteria that tend to combine elements of human proximity with elements of electronic delocalization. Some networks like NASDAQ and Instinet develop above geography and boundaries. Other networks like SEAQ international or GLOBEX develop from geographic hubs - London or Chicago in these cases - without being limited by geographic distance. The need for human proximity does not disappear altogether, witness the human concentration associated with trading rooms and the role of widely available support services of all types in the success of London or New York. But human connections can be combined with increasing creativity with electronic interconnection.

The most recent example I have had to know in my professional life is GLOBEX, a network that will allow products developed and priced on the French Futures market to be traded in Chicago - and soon maybe from almost anywhere - by members of the two Chicago markets and of the other futures markets that will join this network. Once the archetype of a local meeting place, the pit can now become a delocalized electronic place. Believe it or not, the toughest part of this engineering work was not to bring Paris closer to Chicago but Chicago closer to Chicago...

Second, the changing relationship to time: services are the home of the 24-hour-a-day real time economy. Here also, electronic networks now make possible a typc of rclation and co-production that was unthinkable two decades ago. We have to accept that the world can change from mili-second to mili-sccond, quite a challengc for the thinkers in the markets! We must also accept that the time of production can no longer be separated from the time of marketing and consumption...

Financial services (with which I am more directly concerned) epitomize this changing relationship to space and time:

- Until the mid 1970s, banking and financial markets could be understood in terms of a few quite simple basic functions. Credit followed expenditures and earning cycles. Enterprises managed their holdings in a fairly simple manncr. Currencies risks were dealt with also at the relatively slow pace associated with the movements of goods, ships and even plancs. 
- The late 1970s saw higher degree of complexity in the handling of currencies and financial instruments. Providing risk management services became an increasingly important activity in its own right as economic actors in the post Bretton Wood era had to protect themselves against powerful swings in currencies and interest rates not to speak of stock values. Financing, hedging and speculating then had to be seen as functions of equal importance in the working and purpose of financial markets where it was once simply assumed that borrowers came to meet lenders. Servicing the services providers became a new avenue for wealth creation - thereby beginning to challenge our traditional concept of wealth.

- The 1980s then saw a formidable expansion of all types of assets and liabilities from overnight money transfers to long-term zero coupon financing. Financial engineering then became the name of the game, with instant communication among all markets providing a new strategic arena of mind-boggling complexity. Futures and options became more than hedging instruments as they now provide the tools and building blocks for complex and creative financial chemistry. Hence, the various types of instruments - stocks, bonds, and derivatives - are increasingly intertwined through swaps, options and synthetic constructs. Bridges among markets have multiplied in number and depth, also challenging time honored distinctions such as the one between the short-term money market and the long-term financial market.

So, you see, globalization cannot be understood in terms of speed and distance alone. Globalization is also about depth and scope of relation. If you allow me to be slightly irrespectfull at this time of the day, let me conclude this brief review of services and globalization by suggesting that services render economic globalization too important, too intimate to be left to economists alone...

\section{Co-Regulation and the three safety nets}

Services therefore are no longer a back-office function but have become autonomous centers of initiative. The new concepts of wealth, productivity but also those of safety and soundness, need to be re-expressed in light of the new relation to space and time that is the metaphysical counterpart to the service economy.

It is against this background that we must ask the question in your title about "trade liberalization", as well as the question on my mind about the need for a different but effective regulatory framework.

The massive amounts of currency in circulation, the sophistication of instruments, the instant links and arbitrage opportunities among markets have fundamentally changed both the nature of risk and the nature of regulation. The development of services further accelerates - as well as feeds upon - the "deregulation" of markets - at least in the sense of making many of todays's regulations increasingly difficult to enforce. In this sense, trade liberalization as you discuss it here certainly goes hand in hand with what is called deregulation.

But a number of fundamental functions still need to be fulfilled. Property has to be owned and traded, which presupposes that the nature of what is actually owned and traded can be defined and enforced: believe me, in a world of synthetic assets and options on indexes, this is more easily said than done! And, believe me or not, this also calls for new layers of regulation. 
Let me come back to GLOBEX and to the dilemmas that go with global, real time electronic markets.

A market like the global Futures market cannot be developed on the basis of regulatory vacuum. Even the most enthusiastic free market deregulator, if he begins putting some of his money in the network, will quickly call for three levels of safety net:

- The technical safety net is the one required for information based money - money in bits and impulses rather than pesos and schillings - to change hand safety rather than end up in some black hole!

- The rules of conduct safety net is the one required for trust to be there and to make the market possible. Anyone familiar with computer hackling realizes how easily electronic money can also end up in some black pocket!

To me this deontological frontier may well be where we face the most critical challenge, where globalization will become a new source of shared opportunities or just a bad word...

Who is an "insider" in what PROMETHEE labels the network of networks? What is transparency in a world where 7 seconds can be a window of opportunity? What is integrity in a set of intertwined markets and instruments in which it can take less than 2 minutes to substantially influence the value of an index like the French CAC 40 as we have seen recently at the very end of a trading day? As I discuss these and similar questions with other regulators, I often hear that the only instrument we may be left with to confront this new type of risk is the rather primitive regulatory instrument referred to as circuit-breaker.

- The systemic safety net is the one required for electronic money not to flow all over the place: indeed, a computer failure in a compensation network like CHIP quickly takes you in the land of many zeros. A trillion dollar here, a trillion dollar there, and you soon end up talking real money... and not just real money but also real jobs, real monetary policy, real trading system...

Such are the challenges we are learning to live and deal with in a concrete case like GLOBEX. Complexity as a problem has to meet complexity as a solution. This is where we reach the limits of simple words like globalization or deregulation. What I have experienced would be better described as co-regulation, namely the creation of a complex layer of bilateral and pluri-lateral agreements among regulators in different markets as well as in different countries. Such agreements can go from detailed cooperation procedures among regulators on both sides of the same deal - a situation which COB and the US SEC have gradually learnt to master - to long term, multilateral efforts to deal with aspects of the global system risks as we endeavor to do in the Organisation Internationale des Commissions de Valeurs.

Global competition cannot develop on the basis of deregulation only: as I can experience every day, it also calls for extensive cooperation among regulators. And yet, at the same time, regulators are also competing among themselves to provide the most satisfactory market setting and to defend or help promote the role of specific financial places on the global scene. This need to combine greater competition with higher levels of cooperation is central to the governance imperative that I see as critical to the working and development of financial markets. 


\section{Regulatory change: The governance imperative}

Services and notably financial services, therefore, are not just a sector: they are an entry door into a global economy of unprecedented complexity.

Concretely, the deeper issue cannot be defined in the negative terms of de-regulation or removal of barriers. The positive issue at stake, let me venture, is governance.

What I briefly described in the case of financial services and electronic futures markets is part of a broader picture, part of a world set in motion, and increasingly able to selfengineer its own transformation through the development and interconnection of global network of networks. ${ }^{1}$ Ours is a complex world of dynamic interlinks made simple through increasingly complex tools and strategies. ${ }^{2}$

I believe in the role of market forces in bringing about a new generation of opportunities. Yet, spending my professional life in close touch with more than one market, I do not believe in passive trust in some totally invisible cybernetics of individual initiatives and markets. ${ }^{3}$ As Ralf Dahrendorf once made the case, technological advances will materialize - and will translate into new opportunities only to the extent that organizational settings and managerial habits are also upgrated. ${ }^{4}$

Hence the governance imperative faced by regulators like myself as well as by market participants and trade negotiators: what governance is about is the reconciliation of the autonomous, self-creative development taking place around new types of interactions such as the electronic networks I briefly alluded to - with new types of solidarities able to foster initiatives as well as self corrections. ${ }^{5}$

Let me encourage the ThinkNet Commission to continue its discussion of the scenarios that will test the full implications of our changing relationship to time and space and to develop in greater details the recommandations it offered last year in Tokyo on the policies and strategies that can help bring about not just a high-tech networked archipelago but a global networked society. Such discussions, scenarios and recommandations, fragile as they necessarily are, can contribute to this mixture of liberalization and cooperation, imagination and resilience, openness and awareness that lies at the heart of the present governance imperative.

1 ... "animé et rendu totalement présent à soi-même par des réseaux"... J. Saint-Geours, "Eloge de la complexité", Economica, Paris, 1987, p. 5.

2 idem.

3 ... "s'en remettre à une cybernétique des initiatives et des marchés"... Ibid. p. 181 .

4 "les avancements technologiques ne peuvent se développer que si..." p. 184.

${ }^{5}$ Ibid. p. 182. 